\title{
O NUTRICIONISTA ESCLARECIDO PARA A DEFESA DO DIREITO HUMANO À ALIMENTAÇÃO ADEQUADA: CONTRIBUIÇÕES KANTIANAS
}

\author{
S. SOARES \\ Universidade Federal do Rio Grande do Norte \\ ORCID ID: http://orcid.org/0000-0001-7077-9847 \\ sonia.fil@bol.com.br
}

Submetido 20/01/2020 - Aceito 11/05/2020

DOI: $10.15628 /$ holos.2020.9425

\section{RESUMO}

Este ensaio foi extraído da tese da autora e destaca algumas contribuições da filosofia política de Immanuel Kant ao debate atual sobre a efetivação do direito humano à alimentação adequada. O objetivo é delinear o papel do Nutricionista como agente do progresso moral da humanidade. Para tanto, relaciona os avanços jurídicos na garantia dos direitos humanos com a ideia kantiana de progresso para o melhor; em seguida, aborda a importância do esclarecimento, ancorado na ideia de liberdade de expressão do pensamento. Desta forma, reconhece a atualidade do pensamento kantiano e o esclarecimento como uma estratégia relevante na formação do Nutricionista comprometido com a realização do direito humano à alimentação.

PALAVRAS-CHAVE: Alimentação, Direitos Humanos, Kant, Progresso, Esclarecimento.

\section{THE ENLIGHTENED NUTRITIONIST IN DEFENSE OF THE HUMAN RIGHT TO ADEQUATE FOOD: KANT'S CONTRIBUTIONS}

\begin{abstract}
This essay was extracted from the author's thesis and highlights some contributions from Immanuel Kant's political philosophy to the current debate on the realization of the human right to adequate food. The aim is to outline the role of the Nutritionist as an agent of humanity's moral progress. First, it relates the legal advances in guaranteeing human rights with the Kantian idea of progress towards a better state; then, it addresses
\end{abstract} the importance of enlightenment, anchored in the idea of freedom of speech. Thus, it recognizes the significance of Kantian thought and enlightenment as a relevant strategy in the training of Nutritionists committed to the realization of the human right to food.

KEYWORDS: Food, Human Rights, Kant, Progress, Enlightenment. 


\section{APRESENTAÇÃO}

O direito humano à alimentação adequada (DHAA) foi reconhecido no Brasil como direito social fundamental em 2010 (Emenda Constitucional n. 5, 2010). Esta conquista da sociedade brasileira é parte do contexto internacional de progresso na história dos direitos humanos, que tem na Declaração Universal dos Direitos Humanos/DUDH (Organização das Nações Unidas [ONU], 1948) seu marco mais recente, seguido pelos Pactos Internacionais de Direitos Humanos ${ }^{1}$ e seus respectivos Protocolos, cujo caráter vinculante asseguram a proteção dos cidadãos diante da violação dos direitos afirmados na DUDH (Organização das Nações Unidas para a Alimentação e a Agricultura [FAO], 2010).

Neste ensaio, apresentam-se contribuições ao debate sobre a efetivação do DHAA, a partir de referências do pensamento político do filósofo Immanuel Kant, tendo como pressuposto que a exigibilidade dos direitos humanos requer também a liberdade de crítica, na qual repousa, segundo ele, a própria existência da razão (Kant, 1985, p. 608).

Muito já se disse sobre a atualidade do pensamento político de Kant e suas contribuições ao direito internacional (Nour, 2003). Höffe (2005, p. 232-233) considera que Kant "estabelece para a ideia moderna dos direitos humanos o mais elevado padrão de medida, [...] e fundamenta Direito e Estado a partir de princípios de uma razão (jurídico-) prática pura". De acordo com Pinzani (2004, p. 37), a filosofia da história de Kant oferece a melhor chave de leitura para entender plenamente seu pensamento político e jurídico. Para Wood (2008):

A filosofia da história kantiana é guiada, fundamentalmente, primeiro pelo objetivo de descobrir alguma coisa racionalmente compreensível nas ocorrências aparentemente acidentais que compõem a história e, segundo, pela necessidade de relacionar tal entendimento aos nossos objetivos práticos e esperanças práticas. (p. 138).

No caso do direito humano à alimentação, não se pode dizer que os documentos jurídicos que tratam do tema sejam aparentemente acidentais, mas, certamente, eles nos colocam frente à necessidade de relacioná-los aos nossos objetivos práticos e esperanças práticas. No Brasil, a Lei Orgânica de Segurança Alimentar e Nutricional (LOSAN, 2006) reconhece em seu artigo 20 que "a alimentação adequada é um direito fundamental do ser humano, inerente à dignidade da pessoa humana e indispensável à realização dos direitos consagrados na Constituição Federal" (Lei $n$. 11.346, 2006). No entanto, a despeito de alguns resultados positivos no que concerne à escassez de alimentos, não avançamos em relação à garantia do direito à alimentação adequada; o cenário atual se caracteriza pelo excesso de alimentos pouco saudáveis disponíveis no mercado - como os alimentos ultra processados pela indústria - e pela adoção de estilos alimentares decorrentes da modernização do trabalho e intensa urbanização com graves consequências para a saúde

\footnotetext{
${ }^{1}$ São dois os Pactos aprovados pela Assembleia Geral da ONU, em 1966: o Pacto Internacional de Direitos Econômicos, Sociais e Culturais (PIDESC), e o Pacto Internacional de Direitos Civis e Políticos (PIDCP). A alimentação consta como direito humano no artigo 11 do PIDESC.
}

HOLOS, Ano 36, v.5, e9425, 2020 
(Ministério da Saúde, 2011; Câmara Interministerial de Segurança Alimentar e Nutricional [CAISAN], 2018). Além de ainda ser necessário acabar com a fome, precisamos de ações institucionais e individuais para a realização do direito de todos a uma alimentação adequada.

Frente a este cenário, será importante abordar a relação que Kant (1993) estabeleceu entre a ideia de progresso moral consubstanciada no direito natural e outro evento marcante na história dos direitos humanos, a Revolução Francesa. De acordo com D'Aviau de Ternay (1989, p. 14), relembrar a Revolução Francesa a partir da leitura de Kant nos ajudaria a reencontrar desafios atuais, para nos tornarmos "mais comprometidos nos processos de libertação que se impõem aqui hoje". É o próprio Kant (1993) a afirmar que:

semelhante fenómeno não mais se esquece na história da humanidade, porque revelou na natureza humana uma disposição e uma faculdade para o melhor que nenhum político, com a sua subtileza, extrairia do decurso das coisas até agora, e que só a natureza e a liberdade, reunidas no género humano segundo princípios internos do direito, podiam prometer, mas, quanto ao tempo, só de um modo indeterminado e como um acontecimento contingente. (p. 108, grifo do autor).

Para o filósofo de Königsberg, a Revolução teve um caráter moral que se expressou em um modo de pensar, universal e desinteressado, publicamente manifesto, e isto seria prova da disposição moral no gênero humano, um tipo de disposição para o bem, sem a qual seria totalmente impossível "o progresso de um povo para melhor, mesmo no que concerne à menor das suas exigências, a saber, o seu simples direito natural” (Kant, 1993, p. 107).

A evolução do direito natural foi o que levou Kant a inferir o progresso moral do gênero humano. Por este motivo, dada a experiência histórica de progresso no âmbito do direito à alimentação e para impedir retrocessos, diante do perfil nutricional brasileiro (Ministério da Saúde, 2011), considera-se valiosa a ideia de fio condutor da história humana kantiana, representado pela ideia de moralidade como destinação do homem, fortemente associada ao contexto iluminista alemão (Macor, 2008).

Ao retomar a questão do progresso como associado à destinação do homem, Kant trouxe à tona um tema caro ao debate iluminista. ${ }^{2}$ Segundo Ferry (2010, p. 293), para os filósofos alemães a realização do esclarecimento deu-se no grande evento da Revolução Francesa, pois "a Revolução confundia de imediato sua causa com a do sujeito humano que se torna fundamento de seu próprio destino, em suma, com a causa da liberdade compreendida como subjetividade". Para Hinske (1985), a discussão do iluminismo seria inimaginável sem a ideia de destinação do homem, ideia base do iluminismo alemão, que sustentava as três ideias programáticas do ecletismo, pensamento autônomo e maioridade.

É a partir dessas contribuições kantianas que se busca, neste ensaio, delinear o papel do Nutricionista como agente do progresso moral da humanidade. No primeiro momento, a ideia de

2 Considera-se como sinônimo de iluminismo (enlightenment), os termos 'esclarecimento' e 'ilustração', correspondente ao seu sentido genérico conforme apontado por Schmidt (2011).

HOLOS, Ano 36, v.5, e9425, 2020 
progresso para o melhor que tem como causa o gênero humano, conforme retomada por Kant (1993) em O conflito das faculdades, serve como pano de fundo para fazer uma reflexão sobre a 'história empírica' do DHAA, considerando uma possível relação entre o que Kant viu de moral no entusiasmo com a Revolução Francesa e os eventos de elaboração da DUDH e seus desdobramentos. Em seguida, apresenta-se a liberdade de expressão do pensamento, abordada por Kant (1995) nos chamados escritos menores sobre o esclarecimento, para estabelecer seu valor na prática do Nutricionista que se compromete com a realização daquele direito. Espera-se, assim, destacar a atualidade do pensamento kantiano na promoção dos direitos humanos e sua importância na formação do Nutricionista como profissional de saúde.

\section{O PROGRESSO JURÍDICO NA GARANTIA DO DIREITO HUMANO À ALIMENTAÇÃO ADEQUADA: ECOS DA REVOLUÇÃO FRANCESA?}

Ao estabelecer direitos de humanidade, a Revolução Francesa foi, sem dúvida, um marco no progresso político da história humana, que teve na filosofia kantiana um espelho dos seus ideais. Desse acontecimento popular e marcante para a história universal da humanidade resultou não só a queda do absolutismo e instituição da república, mas também a Declaração dos Direitos do Homem e do Cidadão (1789).

Historicamente, o termo 'Declaração' (de origem francesa) expressa um modo público de afirmar algo, de modo solene ou formal, sendo que as declarações, "mais do que assinalar transformações nas atitudes e expectativas gerais [...] ajudaram a tornar efetiva uma transferência de soberania" (Hunt, 2009, p. 113). Proclamar a Declaração, no caso francês, foi um ato soberano de um povo que se deu uma constituição, o que conferiu poder àquele que declara. É o que se lê no Preâmbulo do texto aprovado pela Assembleia Nacional Constituinte da França revolucionária: "os representantes do povo francês [...] resolveram apresentar numa declaração solene os direitos naturais, inalienáveis e sagrados do homem" (Declaração dos direitos do homem e do cidadão, 1789).

A manifestação popular durante o grande evento da Revolução Francesa foi vista por Kant (1993) como uma participação segundo o desejo, na fronteira do entusiasmo, isto é, como participação no bem com paixão. Na análise de Marini (2003), o público externo simpatizou com a exaltação dos revolucionários, nos quais o entusiasmo era vivo, porque estes se viam como defensores do direito do povo.

De fato, mesmo reconhecendo algo de reprovável no entusiasmo como paixão, Kant (1993, p. 103) relaciona o verdadeiro entusiasmo, aquele sem motivação egoísta, ao conceito moral de direito, isto é, um ideal moral que não se baseia no interesse próprio, mas na coexistência dos arbítrios. Foi o entusiasmo pela Revolução Francesa que renovou em Kant suas esperanças no progresso da humanidade, pois ele se encontrava frente a um sinal histórico (prognóstico), cuja causa não podia ser outra, senão a disposição moral do gênero humano para o melhor. Tratava-se daquele momento singular em que a razão prática encontrava a realidade para promover os fins 
da humanidade, mostrando que somente o homem livre pode condicionar positivamente a história. Neste sentido, Bobbio (1992, p. 135) afirma que a tese kantiana da disposição moral da espécie humana como causa do entusiasmo manifesta-se "na afirmação do direito - um direito natural - que tem um povo a não ser impedido, por outras forças de se dar a Constituição civil que creia ser boa". A realização do direito alcançada com a Revolução seria, portanto, um dos fins da história (Perez, 2006; Klein, 2013; Nadal, 2011).

Se para os direitos do homem, a Declaração Francesa foi um marco, para o direito humano à alimentação, podemos partir da Carta Internacional dos Direitos Humanos, documento publicamente manifesto na DUDH (ONU, 1948) e nos Pactos Internacionais de Direitos Humanos (ONU, 1966), que expressou um novo modo de pensar e uma ruptura com os eventos anteriores da guerra e do holocausto, trazendo a esperança de um mundo melhor, na perspectiva de um progresso moral, como se lê no Preâmbulo da DUDH:

Considerando que o desprezo e o desrespeito pelos direitos humanos resultaram em atos bárbaros que ultrajaram a consciência da Humanidade e que o advento de um mundo em que os homens gozem de liberdade de palavra, de crença e da liberdade de viverem a salvo do temor e da necessidade foi proclamado como a mais alta aspiração do homem comum. (ONU, 1948, p. 2, grifo nosso).

Temos, portanto, que as normas jurídicas universalmente válidas e redigidas com base em princípios universais, como a igualdade, a liberdade e a dignidade humana, expressam um avanço da própria história humana (Bobbio, 1992), por isto a análise desse progresso jurídico na história dos direitos humanos traz a marca kantiana (Laffer, 1995). E assim, pode-se reconhecer, tanto no âmbito internacional, das Declarações aos Pactos e Protocolos da ONU, como no âmbito nacional, das Leis e Políticas brasileiras que visam à segurança alimentar e nutricional até o reconhecimento constitucional do direito à alimentação como direito social, aquele sentido de progresso e destinação na história humana, à luz da ideia ordenadora de propósito ou finalidade, tal qual nos fala Kant (1995a, p. 21-37).

Para Laffer (1995, p. 172) com base na Carta da ONU, os direitos humanos tornaram-se um tema global à maneira kantiana, por reconhecerem o ser humano como fim e não meio; "tendo direito a um lugar no mundo; um mundo que encontra um terreno comum entre a Ética e a Política através da associação convergentes [sic] de três grandes temas: direitos humanos e democracia no plano interno e paz no plano internacional" [grifos do autor]. De fato, o direito humano à alimentação passou de mera proclamação, em uma declaração, a direito fundamental, portanto, adquiriu caráter (universal) de obrigação e imputabilidade. Kantianamente falando, governo e povo defenderiam este direito, pois sem esta garantia não teríamos um estado de paz nem o desenvolvimento das capacidades humanas, donde se poderia justificar todo o empenho dos Estados na sua plena efetivação.

A alimentação não constava entre os direitos proclamados na Declaração dos franceses, por outro lado, nas Assembleias da ONU que proclamaram a DUDH e adotaram os Pactos 
Internacionais de Direitos Humanos não havia cidadãos, apenas chefes de Estado, o que pode ter sido um fator negativo que impediu a continuidade do avanço no sentido de acabar com a fome no mundo e realizar o direito de todos à alimentação adequada. Observa-se uma grande distância entre o que chefes de Estado, reunidos em Assembleias, declararam em documentos por eles assinados e o que efetivamente ocorreu em seus territórios nacionais. Desde a Primeira Conferência Mundial sobre Alimentação (1974), na qual foi assinada a Declaração Universal sobre a Erradicação da Fome e Desnutrição que reconheceu "o direito inalienável de cada homem, mulher e criança viver livre da fome e desnutrição" (ONU, 1974), passando pela Cúpula Mundial da Alimentação, que firmou a Declaração de Roma Sobre a Segurança Alimentar Mundial (FAO, 1996) com o objetivo reduzir para a metade o número de pessoas desnutridas até 2015 - o que foi incorporado à Declaração e os Objetivos de Desenvolvimento do Milênio [ODM] (ONU, 2000) -, a meta de erradicar a fome e a miséria tem sido continuamente protelada, a despeito do reconhecimento da possibilidade do seu cumprimento no que diz respeito aos recursos técnicos e tecnológicos necessários. Em 2012, a Assembleia Mundial da Saúde adotou as Metas Globais de 2025 para a Nutrição Materna, de Bebês e Crianças Pequenas, que não serão alcançadas, embora haja esperanças (International Food Policy Research Institute/Instituto Internacional de Pesquisa sobre Políticas Alimentares, 2016). Mais recentemente, com base nos 8 ODM, foi elaborada uma Agenda para o desenvolvimento sustentável (Agenda 2030) com 17 Objetivos de Desenvolvimento Sustentável [ODS], adiando para o ano de 2030, a meta de "acabar com a fome e garantir o acesso de todas as pessoas, em particular os pobres e pessoas em situações vulneráveis, incluindo crianças, a alimentos seguros, nutritivos e suficientes durante todo o ano" (ONU, 2015, 2.1). Outra estratégia relevante foi a adoção da Década de Ação pela Nutrição das Nações Unidas, compreendendo o período entre 2016 e 2025 (ONU, 2016). É fato que o número de pessoas subnutridas está crescendo desde 2014, tendo aumentado de 777 milhões em 2015 para mais de 820 milhões em 2018, sendo que mais de 2 bilhões de pessoas no mundo ainda vivem em um estado de insegurança alimentar moderada ou severa (FAO, IFAD, UNICEF, WFP \& WHO, 2019), algo que, certamente, não favorece o surgimento do entusiasmo, nem o progresso da humanidade.

O conhecimento de tais fatos serve para corroborar a argumentação kantiana sobre a necessidade de o filósofo estar muito bem informado sobre a história empírica, atento aos 'sinais' do progresso, ainda que se atribua à experiência um papel secundário à luz da sua história:

Seria uma falsa interpretação do meu propósito crer que, com a ideia de uma história universal, que tem em certo sentido um fio condutor a priori, pretendi rejeitar a elaboração de uma história concebida de um modo simplesmente empírico; constitui apenas um pensamento acerca do que uma cabeça filosófica (que, de resto, deve estar muito informada no plano histórico) poderia investigar ainda a partir de um outro ponto de vista. Além disso, a riqueza de pormenores, aliás famosa, com que agora se elabora a história da sua época, levará cada qual decerto a considerar com precaução como conseguirá a nossa ulterior descendência carregar com o peso da história que Ihe vamos deixando, ao longo dos séculos. Apreciará, sem dúvida, as épocas mais antigas, cujos documentos já há muito terão desaparecido, somente a partir do ponto de vista do que lhe interessa, a saber, o que os povos e os governos fizeram, ou não, com um propósito cosmopolita. Mas tomar isto em consideração, juntamente com a ânsia de glória dos chefes de Estado e dos seus servidores, para os encaminhar em direç̧ão ao único meio que lhes pode assegurar a recordação

HOLOS, Ano 36, v.5, e9425, 2020 
gloriosa no tempo futuro, pode proporcionar-nos ainda um pequeno motivo para intentar semelhante história filosófica. (Kant, 1995a, p. 37).

Por conseguinte, o ponto de vista de uma 'cabeça filosófica' sobre a história dos direitos humanos torna-se relevante, não apenas para identificar seu sentido numa perspectiva de progresso, como também para encontrar pistas que ajudem a solucionar problemas práticos.

\subsection{Não basta ser direito}

A história empírica do DHAA revela que somente a formalização jurídica não é suficiente para garantir alimentação saudável para todos. Também em Kant (2006, p. 227), o progresso jurídico não se daria por livre acordo entre os indivíduos, mas sim "apenas por meio de progressiva organização dos cidadãos da terra na e para a espécie, como um sistema cosmopolita unificado". Desta forma, compreende-se a participação social como elemento fundamental para a realização do DHAA, essencial ao Estado de Direito, que reflete a ideia mesma de república. Para a defesa dos direitos humanos, no âmbito internacional, a participação do povo foi explicitamente reconhecida como fundamental, na Declaração e Programa de Ação de Viena (ONU, 1993), sendo tal princípio estabelecido nas Diretrizes Voluntárias em apoio à realização progressiva do direito à alimentação adequada no contexto da segurança alimentar nacional (FAO, 2005); já no sistema brasileiro, a participação aparece como diretriz da Política Nacional de Alimentação e Nutrição/PNAN (Portaria n. 2715, 2011) e como princípio organizativo do Sistema de Segurança Alimentar $e$ Nutricional/SISAN (LOSAN, 2006), por meio do qual, políticas, planos, programas e ações são formulados e implementados para a garantia do DHAA. Saliente-se ainda que o Programa Nacional de Direitos Humanos, instituído pelo Decreto n. 7.037/2009³, marcou o reconhecimento da necessidade de "implementação de medidas que garantam à sociedade maior participação no acompanhamento e monitoramento das políticas públicas em Direitos Humanos" (Secretaria Especial dos Direitos Humanos da Presidência da República [SEDH/PR], 2010, p. 23), estabelecendo a interação democrática entre Estado e sociedade civil como instrumento de fortalecimento da democracia participativa em sua primeira diretriz.

A ONU (1999) explicita as obrigações dos Estados para a garantia do DHAA no Comentário Geral n. 12, elaborado para esclarecer o conteúdo do artigo 11 do PIDESC: respeitar, proteger, prover e promover (facilitar). Dentre estas obrigações, incluem-se tanto o cumprimento de prestações positivas, como ações de caráter regulatório e fiscalizador que impeçam obstáculos à sua realização. Em seu art. 23, o documento exige 'obediência total' ao princípio da participação

${ }^{3} \mathrm{O}$ art. 4ㅇ deste decreto n. 7037/2009, o qual instituía o Comitê de Assessoramento e Monitoramento do PNDH com a finalidade de: promover a articulação entre os órgãos e entidades envolvidos na implementação das suas ações programáticas; elaborar os Planos de Ação dos Direitos Humanos; estabelecer indicadores para o acompanhamento, monitoramento e avaliação dos Planos de Ação dos Direitos Humanos; acompanhar a implementação das ações e recomendações; elaborar e aprovar seu regimento interno, foi revogado pelo Decreto n. 10.087, de 05 de novembro de 2019, que revogou diversos decretos normativos.

HOLOS, Ano 36, v.5, e9425, 2020 
na formulação e implementação das estratégias nacionais para o direito à alimentação (ONU, 1999).

Ainda assim, algumas políticas não traduzem na prática o que é direito, revelando aquele desacordo entre a política e a moral, rejeitado por Kant (1995b). Se a política é a aplicação da doutrina do direito, e a moral a teoria dessa doutrina, diz Kant que o desacordo entre ambos resulta impossível, pois isso implicaria uma contradição (lógica). A realidade brasileira, porém, obriga a reconhecer o Estado como responsável por desfigurar os direitos humanos (Comparato, 2010). Nossa insegurança alimentar expressa o desacordo entre moral, direito e política, haja vista que permanecemos em situação de grave desrespeito a um direito humano, fundado na dignidade da pessoa humana, apesar do reconhecimento deste como direito constitucional.

O Brasil ocupa o posto de maior consumidor de agrotóxicos do mundo (Carneiro, Augusto, Rigotto, Friedrich, \& Búrigo, 2015), além de ser o segundo maior produtor mundial de sementes transgênicas, apesar dos estudos que apontam seus riscos (Ferment, Melgarejo, Fernandes, \& Ferraz, 2015) e da rejeição desses produtos nas propostas de todas as Conferências Nacionais de Segurança Alimentar e Nutricional de 2004, 2007, 2011 e 2015 (Conselho Nacional de Segurança Alimentar e Nutricional [CONSEA], 2017). Vê-se aqui uma grave falha do dever do Estado em proteger a saúde pública e a segurança alimentar, diante do profundo desacordo entre a vontade popular e o Estado representado pelas figuras dos poderes republicanos.

Em vista deste quadro de ação ainda pouco eficiente do Estado frente ao novo perfil nutricional brasileiro (Kac, Sichieri, \& Gigante, 2007), torna-se ainda mais necessária a atuação incisiva do cidadão para defender e exigir o seu direito. A partir da ideia do esclarecimento, abordase, a seguir, a importância que assume uma categoria específica de profissionais de saúde, como cidadãos e cidadãs, na defesa do DHAA.

\section{O ESCLARECIMENTO PARA A DEFESA DO DHAA: É PRECISO CRITICAR?}

A manifestação pública do pensamento como expressão da liberdade da razão foi a essência do iluminismo, cujo lema sapere aude exigia ainda a coragem de se manifestar. Tratavase de um direito originário e sagrado da razão humana, "a qual não reconhece nenhum outro juiz que não a própria razão humana universal, onde cada um tem a sua voz" (Kant, 1985, p. 617), que demandava sair de um estado de menoridade, caracterizado pela incapacidade de se orientar segundo seu próprio entendimento (Kant, 1995c). A liberdade de vir a público expor suas ideias ao julgamento público é ilimitada, sendo perfeitamente possível, quase inevitável, que "um público a si mesmo se esclareça" (Kant, 1995d, p. 13). 
É esta liberdade de fazer uso público da razão ${ }^{4}$ a única necessária à ilustração. Impedir tal liberdade é, ao mesmo tempo, roubar também a liberdade de pensar: "o único tesouro que, apesar de todos os encargos civis, ainda nos resta e pelo qual apenas se pode criar um meio contra todos os males" (Kant, 1995c, p. 51). Kant (1995d, p. 18) defende ainda que os súditos possam "fazer uso público da sua própria razão e expor publicamente ao mundo as suas ideias sobre a sua melhor formulação, inclusive por meio de uma ousada crítica da legislação que já existe".

Pode-se, assim, admitir a liberdade de expor o pensamento sobre problemas alimentares como essencial para que se possa pensar sobre eles, única condição de poder resolvê-los. O livre e permanente debate sobre o direito à alimentação possibilitaria a ampliação do próprio pensamento, útil ao autoaperfeiçoamento, e ainda poderia ser fator impeditivo das sociedades secretas $^{5}$ que decidem contra os interesses do povo. Um Nutricionista esclarecido poderia contribuir para a solução de alguns dos nossos problemas alimentares sugerindo modificações na legislação brasileira que, por atos ou omissões, impedisse a realização do DHAA, como é o caso da regulamentação sobre a publicidade de alimentos para crianças (Henriques, Sally, Burlandy, \& Beiler, 2012; Instituto Brasileiro de Defesa do Consumidor [IDEC], Instituto Alana, 2010; Gomes, Castro \& Monteiro, 2010), da legislação que assegura o registro definitivo de um agrotóxico, ou da autorização para o plantio e comercialização de plantas transgênicas (Carneiro et al, 2015).

Mas, como formar um Nutricionista esclarecido? As diretrizes curriculares para o Curso de Nutrição definem assim o perfil deste profissional de saúde:

Nutricionista, com formação generalista, humanista e crítica, capacitado a atuar, visando à segurança alimentar e à atenção dietética, em todas as áreas do conhecimento em que alimentação e nutrição se apresentem fundamentais para a promoção, manutenção e recuperação da saúde e para a prevenção de doenças de indivíduos ou grupos populacionais, contribuindo para a melhoria da qualidade de vida, pautado em princípios éticos, com reflexão sobre a realidade econômica, política, social e cultural. (Resolução n. 5, 2001, art. 3ํ, I)

Uma das habilidades e competências do Nutricionista estabelecidas no art. 4ㅇ deste documento é a comunicação, "na interação com outros profissionais de saúde e o público em geral". Para Kant (1995e, p. 92) "é uma vocação natural da humanidade comunicar reciprocamente, sobretudo a propósito do que diz respeito ao homem em geral", isto é, aquilo que nos é dado pelo ponto de vista do homem como cidadão do mundo, a quem interessa o bem universal da humanidade - à diferença do espectador do mundo, aquele que apenas observa o curso dos acontecimentos. Ao ser trazida ao mundo por seus pais, por exemplo, a criança já nasce

${ }^{4}$ Kant (1995d, p. 13) distingue o uso privado da razão como aquele "que alguém pode fazer da sua razão num certo cargo público ou função a ele confiado". A serviço do governo, estes profissionais não poderiam contradizer suas doutrinas, no entanto, como qualquer cidadão, os profissionais não devem ser impedidos de, como erudito, expor em público suas ideias contra a inconveniência ou injustiça daquelas doutrinas (Kant, 1995d, p. 14).

${ }^{5}$ A expressão é usada por Kant (1995e, p. 92), ao contrapor a obediência sem liberdade, indutora das sociedades secretas, à presença do espírito de liberdade, quando cada um exige ser convencido racionalmente do seu dever.

HOLOS, Ano 36, v.5, e9425, 2020 
cidadã do mundo porque nasce livre e com o direito de ser alimentada e educada por seus pais (Kant, 2013, p. 86).

Deste modo, considerando que, em qualquer lugar que habite, o homem tem direito ao alimento que garanta sua vida, deve ser tarefa do Nutricionista declarar ao público de qualquer lugar do mundo a alimentação como direito universal, assumindo o ponto de vista de um cidadão do mundo, que reconhece que "a violação do direito num lugar da Terra se sente em todos os outros" (Kant, 1995b, p. 140), e assim contribuindo para o esclarecimento de uma comunidade republicana, afinal, para que um povo possa defender os seus direitos é necessário estar acerca deles esclarecido.

\subsection{O nutricionista esclarecido}

Para Kant (1993, p. 106-107) “a ilustração do povo é a sua instrução pública acerca dos seus deveres e direitos no tocante ao Estado a que pertence", de onde emerge a importância de ampliar o debate naquela dimensão do 'público', na qual o povo não seja mero espectador.

No Brasil de hoje, mesmo sob uma constituição republicana que reconhece o direito à alimentação, persiste uma condição perigosamente desfavorável ao esclarecimento. Embora Conselhos e Conferências tenham sido criados para possibilitar a participação do povo nas decisões em assuntos públicos, e a publicidade e o veto à censura sejam preceitos constitucionais, ainda padecemos de qualificação e efetividade na participação social (Gomes, 2015), até em áreas historicamente mais avançadas, como é o caso da saúde (Wendhausen, 2002), além de recentemente ter sido extinto o CONSEA, no primeiro ato presidencial em 2019, o que pode indicar que permanecemos na condição de infante (Comparato, 2000). O 'mutismo brasileiro' (Freire, 1999), o 'pior acidente que teve o Brasil', tal qual referiu Padre Vieira em seu conhecido Sermão da Visitação de Nossa Senhora (1640), segue vivo nos dias de hoje, pela ausência do povo na democracia, especialmente pela fala, que é o modo de afirmar sua soberania.

As condições postas para o esclarecimento do povo brasileiro ainda não foram capazes de avançar no sentido da moralidade para garantir o acordo entre o direito, a política e a moral no campo da alimentação. Além disso, se o contexto kantiano revelou um marco fundamental na evolução dos direitos de humanidade, entre nós, não se pode identificar o entusiasmo que ele presenciou, seja por parte da população, seja por parte dos políticos, frente às questões públicas que dizem respeito à segurança alimentar e nutricional. Por este motivo, é imperativo para nós que qualquer cidadão, como um erudito, possa falar, deixando de ser infante para submeter-se à crítica, criticando.

A época de Kant foi a época da crítica, à qual tudo devia submeter-se, mas havia também dificuldades, "pela grande diferença no modo como as mentes consideram exatamente os mesmos objetos e se consideram mutuamente, [...], a natureza produz um espetáculo digno de ser visto no palco dos observadores e pensadores infinitamente distintos em sua espécie" (Kant, 2006, p. 126). Nesse palco, a verdade há de emergir, não como aquilo que é aceito por alguém na condição de 
menor (observador/espectador), ou seja, como alguém que apenas tomou para si o pensamento que afirmou o outro. No palco da verdade, a grande estrela será a filosofia, com seus princípios e regras do pensar, quais sejam: pensar por si mesmo, isto é, não ser coagido; pensar de modo liberal, isto é, colocando-se, na comunicação com seres humanos, no lugar do outro; e pensar de modo coerente, isto é, sempre de acordo consigo mesmo (Kant, 2006, p. 126). Contudo, mesmo que a maioria dos homens considere difícil e perigosa a passagem para a maioridade, manter-se na posição de menor seria escolher a contramão do progresso para o melhor; para Kant (1995d, p. 16), pode-se até adiar o esclarecimento, mas jamais renunciar a ele, pois isso seria "lesar e calcar aos pés o sagrado direito da humanidade".

Assim colocado, seria grave aquela situação em que se permanece no estado (desejado) de menoridade, quando o povo toma os agentes públicos por taumaturgos e leva o governo a ceder às suas inclinações e até influenciar as doutrinas da Universidade (Kant, 1993). Em tal cômoda situação, não seria necessário declarar a alimentação como direito humano, nem ensinar nas universidades a doutrina do direito aos futuros profissionais, considerando que estes, na sua função de agentes públicos fariam apenas o uso privado da razão, portanto, não poderiam criticar as políticas ou as leis vigentes, nem tampouco apresentar suas contradições com o direito estabelecido; como técnicos do saber, os Nutricionistas exerceriam sua função levando às pessoas os argumentos utilitaristas orientadores das políticas do governo (Ministério da Saúde, 2011), sem contestar sequer sua eficácia, frente à realidade de saúde do povo. Ao exigir o respeito às normas de regulação pública da saúde, por exemplo, o Nutricionista no exercício de sua função na vigilância sanitária - equivalente da polícia médica à época de Kant - nada poderia criticar, não poderia tornar público como aqueles preceitos foram estabelecidos, suas falhas, nem a quais interesses (secretos) estavam atendendo. E não se afirmando o direito, na ausência de acesso à alimentação saudável, o povo nada poderia exigir e permaneceria calado na condição de beneficiário de programas sociais compensatórios da falta do direito; ainda assim, poderiam ser indicadas regras dietéticas, tendo em vista sua saúde e felicidade, afinal, para quem vive na menoridade, a alimentação nada mais pode ser do que um conjunto de regras pragmáticas, visando ao próprio bem-estar corporal, sem qualquer relação com a moral (Soares, 2015).

Kant (1995d, p. 12) tem razão ao dizer que: "preceitos e fórmulas, instrumentos mecânicos do uso racional ou, antes, do mau uso dos seus dons naturais, são os grilhões de uma menoridade perpétua". As Ciências da Saúde, incluída a Nutrição, são, sem dúvida, portadoras de muitos grilhões, na forma de preceitos e fórmulas, seus profissionais podem atuar sobre o povo, não para esclarecê-los, mas para mantê-los sob seu jugo. O resultado seria aquele estado em que, de um lado, o povo quer ser dirigido e dominado, de outro, o profissional toma para si a responsabilidade de estabelecer o melhor benefício para o povo, a quem não caberia se esforçar.

É diante da possibilidade desta realidade que se impõe, tanto a necessidade do esclarecimento para os profissionais Nutricionistas, como a exigência de coragem para expor publicamente seus pensamentos, inclusive para criticar as doutrinas ensinadas no âmbito privado ou leis já aprovadas, bem como para propor novos estatutos. É o que Kant esperaria de um 'erudito 
não egoísta' ${ }^{6}$, um verdadeiro homem de ciência, a quem não lhe falta humanidade porque sabe conviver com o outro, portador de outro ponto de vista sobre seu saber.

Deste modo, uma forma de superar os obstáculos à realização do DHAA, tomando o fio condutor da história em Kant, seria estabelecer múltiplas ágoras de diálogos permanentes sobre a alimentação que permitiriam (re)formular leis com a necessária participação ativa do cidadão e sua disposição para a comunicação. O papel do Nutricionista esclarecido neste processo implicaria reconhecer na sua ciência uma finalidade de aplicação ao mundo, tendo em vista um progresso moral da humanidade.

\section{CONSIDERAÇÕES FINAIS}

A inclusão da alimentação como direito fundamental foi um momento singular na história brasileira, uma grande vitória para os defensores dos direitos humanos e um marco no sentido da libertação humana do flagelo da fome e da miséria, não mais vistos como fenômenos naturalizados. Na defesa dos direitos humanos, a filosofia de Kant oferece fundamentos para a prática do profissional Nutricionista comprometido com o esclarecimento, frente ao enorme desafio que se tem hoje para efetivar o DHAA e manter a experiência histórica de progresso, impedindo retrocessos.

Deste modo, o Nutricionista esclarecido contribui para o progresso moral da humanidade, ao defender o DHAA, a partir do debate público, exercendo sua liberdade de crítica. No espaço público, este profissional, orientado pela filosofia, deve ser ator permanente, capaz de estimular a participação popular na luta pela realização daquele direito que é de todos.

\section{REFERÊNCIAS}

Bobbio, N. (1992). A era dos direitos (10a ed., C. N. Coutinho, trad.). Rio de Janeiro: Campus.

Câmara Interministerial de Segurança Alimentar e Nutricional (2018). Plano Nacional de Segurança Alimentar e Nutricional - PLANSAN 2016-2019 Revisado. Brasília, DF: CAISAN. Recuperado de http://www.mds.gov.br/webarquivos/arquivo/seguranca alimentar/caisan/Publicacao/Caisa n N acional/PLANSAN\%202016-2019 revisado completo.pdf.

\footnotetext{
${ }^{6}$ Kant (como citado em Conceição, 2013, p. 131) usa a figura do ciclope para referir-se ao egoísta da ciência, aquele erudito a quem falta humanidade, pela ausência de convivência com o outro que lhe propicie outro ponto de vista sobre seu saber.
} 
Carneiro, F. F., Augusto, L. G. S., Rigotto, R. M., Friedrich, K., \& Búrigo, A. C. (Orgs.). (2015). Dossiê Abrasco: Um alerta sobre os impactos dos agrotóxicos na saúde. Rio de Janeiro: EPSJV.

Comparato, F. K. (2000). Sentido e alcance do processo eleitoral no regime democrático. Estudos Avançados, 14(38), 307-320. Recuperado de https://doi.org/10.1590/S010340142000000100018.

Comparato, F. K. (2010). A afirmação histórica dos direitos humanos (7a ed). São Paulo: Saraiva.

Conceição, J. V. C. (2013). Anthropologie transscendentalis: uma reorientação da teoria dos juízos em Kant. Kant e-Prints, 8(2), 131-149.

Conselho Nacional de Segurança Alimentar e Nutricional. CONSEA (Org.). Relatórios de Conferência. Recuperado de http://www4.planalto.gov.br/consea/eventos/conferencias.

D'Aviau de Ternay, H. (1989). Kant e a revolução francesa. Síntese: Revista de Filosofia, 16(47), 1328. Recuperado de http://www.faje.edu.br/periodicos/index.php/Sintese/article/view/1756.

Declaração Universal dos Direitos do Homem e do Cidadão (1789). Recuperado de http://www.dhnet.org.br/direitos/anthist/dec1793.htm.

Decreto n. 7.037, de 21 de dezembro de 2009. Atualizado pelo Decreto n. 7.177, de 12 de maio de 2010. Aprova o Programa Nacional de Direitos Humanos - PNDH-3 e dá outras providências. Recuperado de http://www.planalto.gov.br/ccivil_03/_Ato20072010/2009/Decreto/D7037.htm.

Emenda Constitucional n. 64, de 04 de fevereiro de 2010. Altera o art. 6o da Constituição Federal, para introduzir a alimentação como direito social. Recuperado de http://www.planalto.gov.br/ccivil_03/constituicao/Emendas/Emc/emc64.htm.

FAO, IFAD, UNICEF, WFP \& WHO. (2019). The State of Food Security and Nutrition in the World 2019. Safeguarding against economic slowdowns and downturns. Rome: FAO.

Ferment, G., Melgarejo, L., Fernandes, G. B., \& Ferraz, J. M. (2015). Lavouras transgênicas - riscos e incertezas: mais de 750 estudos desprezados pelos órgãos reguladores de OGMs. Brasília: Ministério do Desenvolvimento Agrário.

Ferry, L. (2010). Uma leitura das três críticas (2a ed., K. Jannini, trad.). Rio de Janeiro: Difel.

Freire, P. (1999). Educação como prática da liberdade (23a ed.). Rio de Janeiro: Paz e Terra.

Gomes, E. G. M. (2015). Conselhos gestores de políticas públicas: aspectos teóricos sobre o potencial de controle social democrático e eficiente. Cad. EBAPE.BR, 13(4), 894-909. http://dx.doi.org/10.1590/1679-395123196.

Gomes, F. S., Castro, I. R. R., \& Monteiro, C. A. (2010). Publicidade de alimentos no Brasil: avanços e desafios. Ciência e Cultura, 62(4), 48-51. Recuperado de 
http://cienciaecultura.bvs.br/scielo.php?script=sci_arttext\&pid=S0009-

$67252010000400015 \& \operatorname{lng}=e n \&$ tlng=pt.

Henriques, P., Sally, E. O., Burlandy, L., \& Beiler, R. M. (2012). Regulamentação da propaganda de alimentos infantis como estratégia para a promoção da saúde. Ciência \& Saúde Coletiva, 17(2), 481-490. https://dx.doi.org/10.1590/S1413-81232012000200021.

Hinske, N. (1985). Le idee portanti dell'illuminismo tedesco: tentativo di una tipologia (S. F. Bertoletti, trad.). Annali della Scuola Normale Superiore di Pisa: Classe di Lettere e Filosofia, 15 (3), 997-1.034.

Höffe, O. (2005). Immanuel Kant (C. V. Hamm \& V. Rohden, trad.). São Paulo: Martins Fontes.

Hunt, L. (2009). A invenção dos direitos humanos: uma história (R. Eichenberg, trad.). São Paulo: Companhia das Letras.

Instituto Brasileiro de Defesa do Consumidor/Instituto Alana. Projeto Criança e Consumo. (2011). Publicidade infantil: multinacionais não aplicam padrões internacionais no Brasil. Recuperado de https://idec.org.br/em-acao/em-foco/publicidade-infantil-multinacionais-nao-aplicampadroes-internacionais-no-brasil.

Instituto Internacional de Pesquisa sobre Políticas Alimentares. International Food Policy Research Institute. (2016). Relatório sobre a Nutrição Mundial 2016: da Promessa ao Impacto: Erradicar a Má Nutrição até 2030. Washington (EUA). Recuperado de https://www.ifpri.org/node/16079.

Kac, G., Sichieri, R. \& Gigante, D. P. (Orgs.). (2007). Epidemiologia Nutricional. Rio de Janeiro: Fiocruz/Atheneu.

Kant, I. (1985). Crítica da razão pura (5a ed., M. P. Santos \& A. F. Morujão, trad.). Lisboa: Fundação Calouste Gulbenkian.

Kant, I. (1993). O conflito das faculdades (A. Morão, trad.). Coleção "Textos filosóficos". Lisboa: 70.

Kant, I. (1995). A paz perpétua e outros opúsculos (A. Morão, trad.). Coleção "Textos filosóficos". Lisboa: 70.

Kant, I. (1995a). Ideia de uma história universal com um propósito cosmopolita. In: A paz perpétua e outros opúsculos (A. Morão, trad.), pp. 21-37. Coleção "Textos filosóficos". Lisboa: 70.

Kant, I. (1995b). A paz perpétua: um projecto filosófico. In: A paz perpétua e outros opúsculos (A. Morão, trad.), pp. 119-171. Coleção "Textos filosóficos". Lisboa: 70.

Kant, I. (1995c). Que significa orientar-se no pensamento. In: A paz perpétua e outros opúsculos (A. Morão, trad.), pp. 39-55. Coleção "Textos filosóficos". Lisboa: 70. 
Kant, I. (1995d). Resposta à pergunta: "o que é o iluminismo?". In: A paz perpétua e outros opúsculos (A. Morão, trad.), pp. 11-19. Coleção "Textos filosóficos". Lisboa: 70.

Kant, I. (1995e). Sobre a expressão corrente: Isto pode ser correto na teoria, mas nada vale na prática. In: A paz perpétua e outros opúsculos (A. Morão, trad.), pp. 57-101. Coleção "Textos filosóficos". Lisboa: 70.

Kant, I. (2006). Antropologia de um ponto de vista pragmático (C. A. Martins, trad.). São Paulo: lluminuras.

Kant, I. (2013). Metafísica dos Costumes (C. A. Martins, trad. primeira parte; B. N. D. Kosbiau \& M. Hulshor, trad. segunda parte). Petrópolis: Vozes.

Klein, J. T. (2013). Kant sobre o progresso na história. Ethic@, 12(1), 67-100. https://doi.org/10.5007/1677-2954.2013v12n1p67

Laffer, C. (1995). A ONU e os direitos humanos. Estudos Avançados, 9(25), 169-185. Recuperado de http://www.revistas.usp.br/eav/article/view/8895.

Lei n. 11.346, de 15 de setembro de 2006. Lei Orgânica de Segurança Alimentar e Nutricional. Cria o Sistema Nacional de Segurança Alimentar e Nutricional. SISAN com vistas em assegurar o direito humano à alimentação adequada e dá outras providências. Recuperado de http://www.planalto.gov.br/ccivil_03/_ato2004-2006/2006/lei/l11346.htm.

Macor, L. A. (2008). L'accezione kantiana de Bestimmung des Menschen e la sua prima ricezione (1784-1793). Kant e-Prints, 3(2), 211-222.

Marini, G. (2003). Considerazioni su storia pronosticante ed entusiasmo. In: Bertani, C. , \& Pranteda M. A. (Orgs.). Kant e il conflitto delle facoltà: Ermeneutica, progresso storico, medicina, pp. 213-229. Bologna: II Mulino.

Ministério da Saúde. (2011). Plano de ações estratégicas para o enfrentamento das doenças crônicas não transmissíveis (DCNT) no Brasil 2011-2022. Brasília, DF: Ministério da Saúde. 160 p. [Série B. Textos Básicos de Saúde].

Nadal, B. (2011). Progresso e moral na filosofia da história de Kant. Tese de Doutorado, Faculdade de Filosofia, Letras e Ciências Humanas, Universidade de São Paulo, São Paulo. doi:10.11606/T.8.2011.tde-14062012-155924. Recuperado de www.teses.usp.br.

Nour, S. (2003). Os cosmopolitas. Kant e os "temas kantianos" em relações internacionais. Contexto Internacional, 25(1), 7-16.

Organização das Nações Unidas. (1948). Declaração Universal dos Direitos Humanos. Recuperado de https://nacoesunidas.org/wp-content/uploads/2018/10/DUDH.pdf.

ONU. (1974). Declaração Universal sobre Erradicação da Fome e Desnutrição. Recuperado de http://www.legislacion.bvsalud.org/php/level.php?lang=pt\&component=37\&item=5. 
ONU. (1993). Declaração de Viena e Programa de Ação. Recuperado de http://www.dhnet.org.br/direitos/anthist/viena/viena.html.

ONU. (1999). Comentário Geral n. 12: Direito Humano à Alimentação Adequada. Recuperado de http://pfdc.pgr.mpf.mp.br/atuacao-e-conteudos-de-apoio/publicacoes/alimentacaoadequada/Comentario\%20Geral\%20No\%2012.pdf.

ONU. (2000). Declaração e os Objetivos de Desenvolvimento do Milênio. Recuperado de https://nacoesunidas.org/tema/odm/.

ONU. (2015). Agenda do Desenvolvimento Sustentável. Recuperado de https://nacoesunidas.org/pos2015/agenda2030/.

ONU. (2016). Década de Ação pela Nutrição. Recuperado de https://www.un.org/nutrition/home.

Organização das Nações Unidas para a alimentação e a agricultura. (1996). Declaração de Roma sobre a Segurança Alimentar Mundial. Recuperado de http://www.fao.org/docrep/003/w3613p/w3613p00.HTM.

Organização das Nações Unidas para a alimentação e a agricultura. (2005). Diretrizes voluntárias em apoio à realização progressiva do direito à alimentação adequada no contexto da segurança alimentar nacional. Roma: FAO.

Organização das Nações Unidas para a alimentação e a agricultura. (2010). Guía para legis/ar sobre el derecho a la alimentación. Roma: FAO.

Portaria n. 2715, de 17 de novembro de 2011. Atualiza a Política Nacional de Alimentação e Nutrição. Recuperado

de http://bvsms.saude.gov.br/bvs/saudelegis/gm/2011/prt2715_17_11_2011.html.

Perez, D. O. (2006). Os significados da história em Kant. Philosophica, 28, 67-107.

Pinzani, A. (2004). Costretti alla libertà? Sulla filosofia della storia kantiana e sul concetto di autonomia in essa implicito. In: Pinzani, A., \& Moneti, M. Diritto, politica e moralità in Kant, pp. 37-49. Milano: Mondadori.

Resolução n. 5, de 07 de novembro de 2001. Institui Diretrizes Curriculares Nacionais do Curso de Graduação em Nutrição. Diário Oficial da União, Brasília, 9 de novembro de 2001. Seção 1, p. 39.

Secretaria Especial dos Direitos Humanos da Presidência da República. Programa Nacional de Direitos Humanos (PNDH-3). Brasília: SEDH/PR, 2010.

Schmidt, J. (2011). What counts as an Answer to the question "what is enlightenment". Recuperado de

https://www.academia.edu/3751155/What_Counts_as_an_Answer_to_the_Question_What _is_Enlightenment_.

HOLOS, Ano 36, v.5, e9425, 2020 
Soares, S. (2016). Ética da alimentação: Porque devemos, segundo Kant, escolher uma alimentação adequada e saudável. Tese de Doutorado, Universidade Federal do Rio Grande do Norte; Universidade Federal da Paraíba; Universidade Federal de Pernambuco, Natal, RN, Brasil. Recuperado de https://repositorio.ufrn.br/jspui/handle/123456789/20881.

Vieira, A. Sermão da visitação de Nossa Senhora. Recuperado de http://www.literaturabrasileira.ufsc.br/_documents/0006-02072.html.

Wendhaysen, Á. (2002). O duplo sentido do controle social: (Des) caminhos da participação em saúde. Itajaí: Univali.

Wood, A. (2008). Kant (D. V. Dutra, trad.). Porto Alegre: Artmed.

\section{COMO CITAR ESTE ARTIGO:}

Soares, S. (2020). O Nutricionista esclarecido para a defesa do direito humano à alimentação adequada: Contribuições Kantianas. Holos. 36(5), 1-17.

\section{SOBRE OS AUTORES}

\section{S. SOARES}

Nutricionista, doutora em ética, professora do Departamento de Nutrição/UFRN. E-mail: soniafilos@yahoo.com

ORCID ID: http://orcid.org/0000-0001-7077-9847

Editor(a) Responsável: Francinaide de Lima Silva Nascimento Pareceristas Ad Hoc: Jaqueline Engelmann e Vicente Zatti

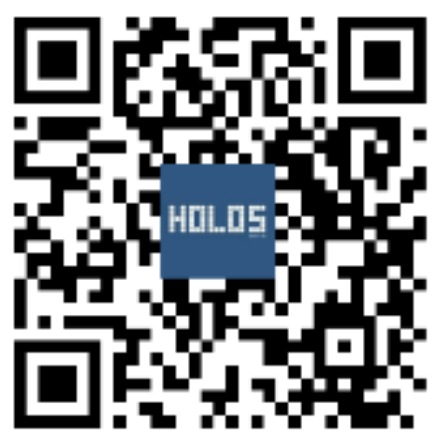

